\title{
Impression cytology following mitomycin C therapy for ocular surface squamous neoplasia
}

Penelope A McKelvie, Mark Daniell

\begin{abstract}
Backgroundlaims-Topical mitomycin C (MMC) therapy has been used for treatment of ocular surface squamous neoplasia (OSSN) since 1994. Relatively few studies have reported the cellular changes in ocular surface following MMC.

Methods-Impression cytology was studied in four patients with ocular surface squamous neoplasia, either primary or recurrence after previous excisional biopsy. The authors studied samples obtained using Millipore filters at intervals between 4 and 17 weeks after commencement of MMC, and compared them with pretreatment cytology.

Results-MMC induced changes of cytomegaly, cytoplasmic vacuolation, nucleomegaly with nuclear wrinkling, and binucleation or multinucleation were seen in some cells in all samples. However, nuclear/cytoplasmic (N/C) ratio in these enlarged cells was normal. These changes mimicked those seen following radiation therapy in uterine cervix. Changes of increased nuclear and cell size with increased N/C ratio were seen in some dysplastic cells. The predominant form of cell death was apoptosis with fewer cells showing necrosis.

Conclusions-MMC appears to produce cell death in OSSN by apoptosis and necrosis. Cellular changes related to MMC mimic those caused by radiationcytomegaly, nucleomegaly, and vacuolation. MMC related changes may persist in ocular surface epithelium for at least 8 months following MMC therapy.

(Br f Ophthalmol 2001;85:1115-1119)
\end{abstract}

Department of

Anatomical Pathology, St Vincent's Hospital, Melbourne, Victoria, Australia

P A McKelvie

Royal Victorian Eye and Ear Hospital, East

Melbourne, Victoria,

Australia

M Daniell

Correspondence to:

Penelope McKelvie,

Anatomical Pathology, St

Vincent's Hospital, 41

Victoria Parade, Fitzroy, Vic

3065, Australia

mckelvpa.svhm.org.au

Accepted for publication 27 March 2001
The use of mitomycin C (MMC), a DNA alkylating agent, in the treatment of ocular surface squamous neoplasia (OSSN) was first reported in 1994. ${ }^{1}$ Results of a multicentre trial published in 1997 indicated the efficacy of MMC in treatment of both primary tumours and recurrent disease following excisional

Table 1 Patient details

\begin{tabular}{|c|c|c|c|c|}
\hline Patient & Ocular history & Current disease & $\begin{array}{l}\text { Cycles of } M M C \\
(\times 7 \text { days })\end{array}$ & $\begin{array}{l}\text { Cytology after } \\
\text { starting } M M C\end{array}$ \\
\hline 1 EB. $M, 68$ & $\begin{array}{l}\text { June 1998. R CIN excisional biopsy. Jan } \\
2000 \text {. R CIS, nasal and temporal, } \\
\text { excisional biopsy, incompletely excised }\end{array}$ & $\begin{array}{l}\text { Recurrence July } 2000 \mathrm{R} \\
\text { limbus ( } 6 \text { months) }\end{array}$ & $\begin{array}{l}2 \text { in January } 2000 . \\
2 \text { in July, August } \\
2000\end{array}$ & $\begin{array}{l}4 \text { weeks. } 8 \text { weeks. } \\
15 \text { weeks }\end{array}$ \\
\hline 2 GV. M, 77 & $\begin{array}{l}\text { March } 2000 . \text { L limbus. Severe } \\
\text { dysplasia, incompletely excised }\end{array}$ & $\begin{array}{l}\text { Recurrence July } 2000 . \mathrm{L} \\
\text { limbus ( } 6 \text { months) }\end{array}$ & $\begin{array}{l}2 \text { in July, August } \\
2000\end{array}$ & 4 weeks. 8 weeks \\
\hline 3 JS. F, 44 & $\begin{array}{l}\text { April 1998. L CIS, excisional biopsy, } \\
\text { incompletely excised. Dec 1999. R CIS, } \\
\text { excisional biopsy, incompletely excised }\end{array}$ & $\begin{array}{l}\text { June } 2000 . \text { Recurrence } \\
\text { L cornea. ( } 26 \text { months) }\end{array}$ & $\begin{array}{l}2 \text { cycles in June and } \\
\text { July, } 2000\end{array}$ & 8.5 weeks. 15 weeks \\
\hline 4 RC. $M, 75$ & Nil & $\begin{array}{l}\text { June } 2000 . \text { Clinical L } \\
\text { OSSN }\end{array}$ & $\begin{array}{l}3 \text { cycles June, July } \\
2000 .\end{array}$ & $\begin{array}{l}8 \text { weeks. } 12 \text { weeks. } \\
17 \text { weeks }\end{array}$ \\
\hline
\end{tabular}
MMC therapy for OSSN before May 2000.

\section{CYTOLOGY}

All patients in the prospective study had the clinical diagnosis of OSSN (in 2000) confirmed by impression cytology using Millipore filters. ${ }^{410}$ The filters were fixed in $95 \%$ alcohol, biopsy. ${ }^{2}$ With the increased use of impression cytology in the diagnosis and follow up of OSSN, ${ }^{34}$ the question of whether cellular changes induced by MMC in normal cells of the ocular surface may result in possible confusion with dysplastic cells has been raised.

Although there is considerable literature on cytology of urinary bladder following intravesical MMC, ${ }^{56}$ there have been relatively few reports of cytology ${ }^{7}$ or histology of the ocular surface $^{89}$ following MMC therapy for ocular surface melanocytic or squamous neoplasia. Changes induced by MMC therapy may mimic those of malignancy. ${ }^{7}$ Although these cellular changes may last for years in urinary bladder, similar long term cytological studies of the ocular surface do not exist. We undertook a prospective study of impression cytology following MMC therapy in patients with recurrent and primary OSSN.

\section{Materials and methods}

PATIENTS

The prospective arm of the study included samples from four patients from May 2000 (Table 1). The four patients included three males aged $68-75$ years and one female aged 44 years. Three patients had a history of OSSN, treated by excisional biopsy with two patients having had two biopsies. These three patients suffered recurrent disease 6-26 months after excisional biopsy with incomplete surgical margins. One patient had primary OSSN. All patients were treated with topical MMC $0.04 \%$ four times daily for a week followed by a week off. This cycle was repeated up to three times.

The retrospective component of the study involved review of impression cytology specimens received on patients who had received 

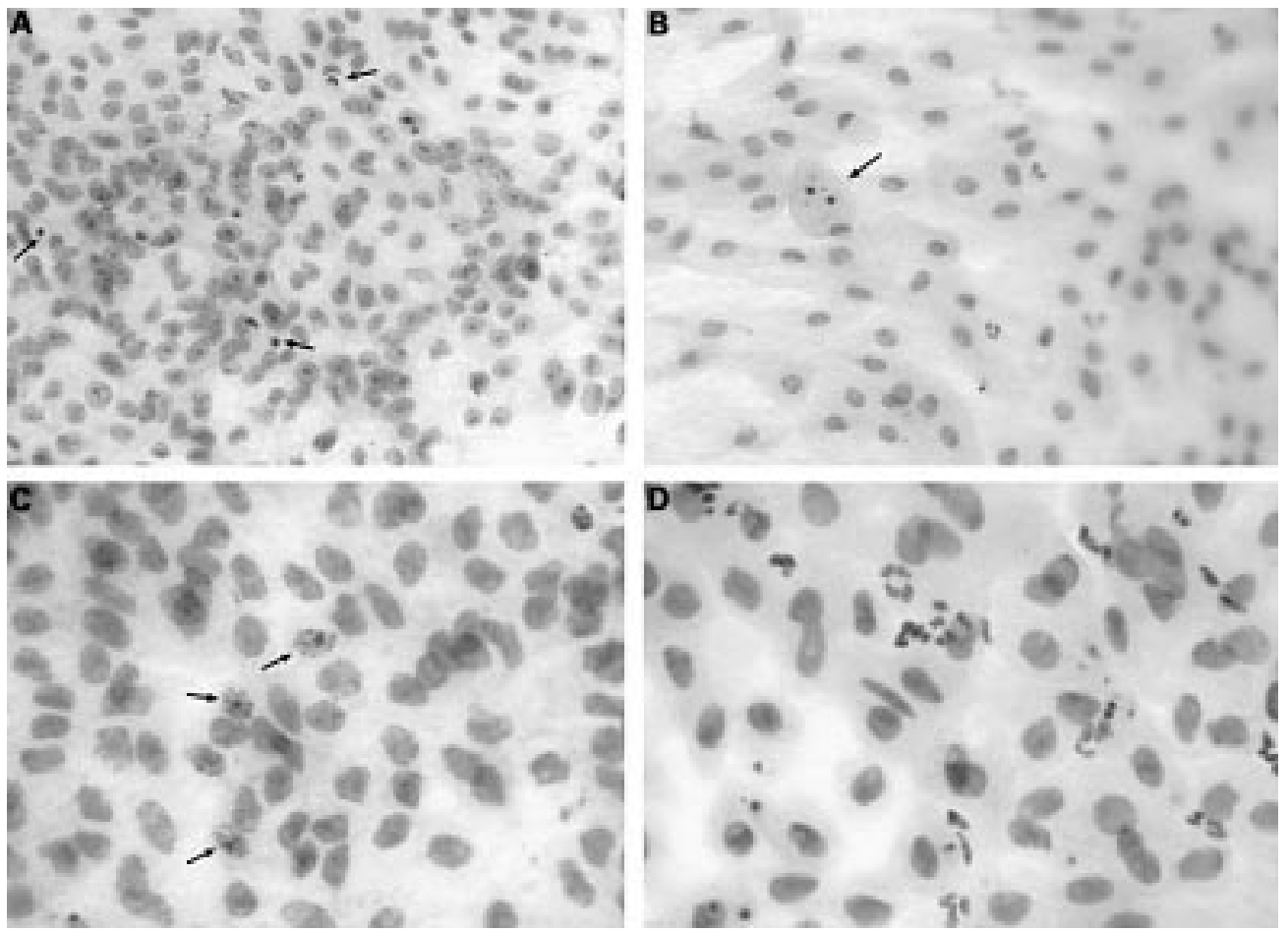

Figure 1 (A) High power of apoptotic bodies (arrows) associated with dysplastic cells, in patient 1 at 4 weeks.

Haematoxylin and eosin. Original magnification $\times 200$. (B) High power of apoptotic body (arrow) associated with normal cells, in patient 1 at 4 weeks. Haematoxylin and eosin. Original magnification $\times 200$. (C) High power of karyorrhectic nuclei (arrows) in patient 1 at 8 weeks. Haematoxylin and eosin. Original magnification $\times 400$. (D) High power of mild acute inflammatory infiltrate of neutrophils in patient 4 at 12 weeks. Haematoxylin and eosin. Original magnification $\times 400$.

stained with haematoxylin and eosin, removed from the cylinders, and mounted on glass slides. ${ }^{4}$ One of the authors (PMcK) examined the cytology specimens with detailed photography. Ten samples were taken from these patients at intervals of $4-17$ weeks (Table 1), including samples from the lesional zone in all four patients when the CIN had resolved clinically (8-12 weeks). One patient suffered a clinical recurrence, confirmed by impression cytology at 15 weeks.

\section{Results}

MODE OF CELL DEATH ASSOCIATED WITH MMC Apoptotic bodies (condensations of cytoplasm plus or minus nucleus) were seen in all samples in the prospective study from 4-12 weeks after commencing MMC (5 days to 43 days after the end of the last cycle) with smaller numbers seen at the longer time intervals.

Early samples at 4 weeks showed up to nine bodies per $\times 200$ high power field (HPF) within sheets of dysplastic cells (Fig 1A). Occasional apoptotic bodies were also seen in sheets of cells without obvious dysplastic cells at 4 weeks (Fig 1B).

There was also evidence of necrosis with scattered cells showing karyorrhexis and pyknosis (Fig 1C). Up to three karyorrhectic nuclei were seen per $\times 200 \mathrm{HPF}$ at 8 weeks. Overall, apoptosis seemed more prominent than necrosis as an indicator of cell death. Necrotic cells were more numerous in early samples, but karyorrhectic nuclei were seen for up to 8 weeks. A mild acute inflammatory infiltrate of neutrophils (Fig 1D), which accompanied the necrosis, was seen in almost all prospective samples with a moderate to heavy inflammatory infiltrate seen in patient 2 at 8 weeks.

CELLULAR CHANGES ASSOCIATED WITH MMC

Cellular changes were seen in some normal ocular surface epithelial cells and some dysplastic cells in all samples from 4-12 weeks, and in normal epithelial cells in one of the retrospective cases at 8 months.

Changes in normal cells included:

(1) Vacuolisation of cytoplasm that ranged from fine (fibrillary appearance) to large vacuoles obscuring nucleus (Fig 2A, B, and C). Vacuoles were single or multiple.

(2) Increased cell size due to increased cytoplasm. In these cells, the nucleus was enlarged or normal size (Fig $2 \mathrm{~B}$ and $\mathrm{C}$ ). The nuclear/cytoplasmic (N/C) ratio was not increased in these enlarged normal cells.

(3) Multiple nuclei or binucleation (Fig 2D) could be seen uncommonly.

(4) Wrinkled nuclei with irregular nuclear outline or hyperchromatic nuclei (Fig 2B and C) were seen.

Changes in some dysplastic cells were similar, particularly the increased size of the cell due to increased cytoplasm. Two patients (1 and 2) had small pretreatment dysplastic cells with little cytoplasm and large hyperchromatic nuclei with coarse uneven chromatin and nucleoli. The increase in cytoplasmic size in these cases was more prominent than the change in nuclear size, but the nuclei still had dysplastic features compared with the enlarged normal nuclei (Fig 3A and B). 

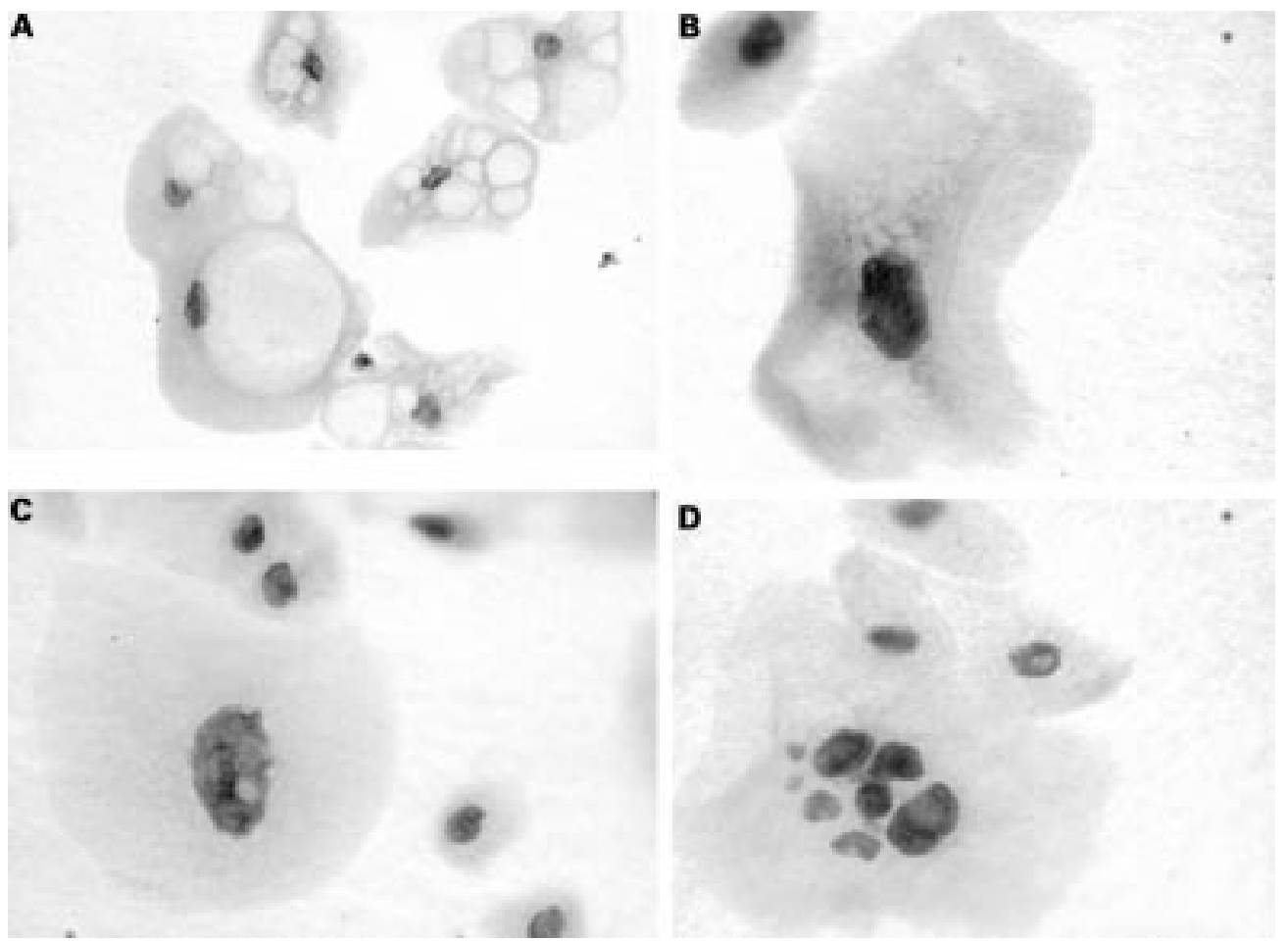

Figure 2 (A) High power of cell showing MMC related changes in patient 4 at 8 weeks; multivacuolated cells with small nuclei related to MMC. Haematoxylin and eosin. Original magnification $\times 200$. (B) High power of enlarged epithelial cell with $M M C$ relate changes in patient 4 at 12 weeks; cytomegaly, vacuolated cytoplasm, hyperchromatic enlarged nucleus with wrinkling compared with the normal cell in top left. Haematoxylin and eosin. Original magnification $\times 400$. (C) High power of another cell with MMC related changes in patient 4 at 12 weeks; cytomegaly, enlarged irregular nuclei with vacuolation compared with normals above and to lower right. The grainy texture is due to the Millipore filter on which cells are collected. Haematoxylin and eosin. Original magnification $\times 400$. (D) High power of multinucleated cell related to $M M C$ in patient 4 at 12 weeks. Haematoxylin and eosin. Original magnification $\times 400$.

Small numbers of dysplastic cells were still present in cytology specimens in all patients taken when there was no clinical disease.

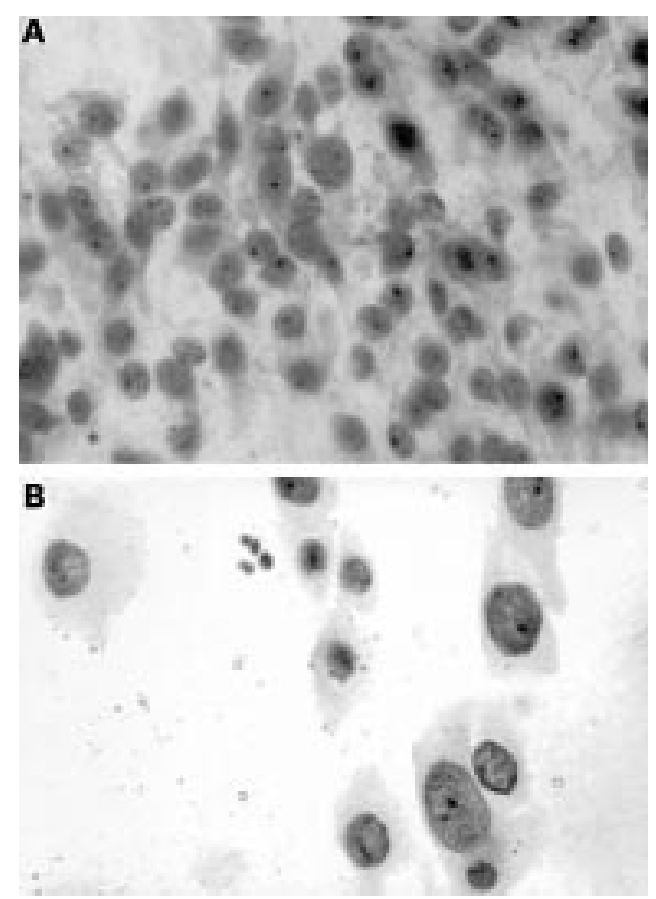

Figure 3 (A) High power of pre-MMC dysplastic cells in patient 2. Haematoxylin and eosin. Original magnification $\times 400$. (B) High power of case 2 at 32 days after MMC, dysplastic cells with increased size of nucleus and cytoplasm (arrows) but persistent high N/C ratio. Haematoxylin and eosin. Original magnification $\times 400$.

\section{PERSISTENCE OF CELLULAR CHANGES}

Cellular changes related to MMC were seen up to 12 weeks after commencement of MMC therapy in the prospective series. One patient sampled at 17 weeks, after completion of three cycles of MMC, had no evidence of MMC related changes. In one of the retrospective cases examined at 8 months after starting MMC therapy (and 7 months after the last dose), there were occasional enlarged cells with large pale nuclei and occasional binucleated cells.

\section{Discussion}

MMC is an antibiotic derived from Streptomyces caespitosus. After intracellular enzymatic or spontaneous chemical reduction, mitomycin becomes a bifunctional or trifunctional alkylating agent, which is able to inhibit DNA synthesis and cross link DNA between adenine and guanine at three different sites. ${ }^{11}$ MMC also causes single strand breakage of DNA and chromosomal breaks. Although MMC acts primarily during the late $\mathrm{G} 1$ and $\mathrm{S}$ phases, it is non-cell cycle specific. DNA damage frequently triggers death by apoptosis. ${ }^{12}$ DNA damage to eukaryotic cells induces complex responses, including recognition of DNA injury, assessment of damage during check points, and initiation of appropriate response (DNA repair or cell death). ${ }^{12}$ It is now clear that antineoplastic agents which cause DNA damage induce apoptosis in tumour cells, but 
only cell cycle arrest in normal cell counterparts, because of varying apoptosis thresholds. ${ }^{13}$ Recent studies of the effects of MMC on bladder cancers show induction of apoptosis in an ex vivo model of bladder cancer, with evidence suggesting that this ex vivo response matches the clinical outcome. ${ }^{14}$

We have demonstrated using impression cytology that apoptosis appears to be a major mode of cell death due to MMC in OSSN with apoptotic bodies evident at the earliest time interval examined (4 weeks) and up to 12 weeks after starting therapy. The number of apoptotic bodies observed decreased as the tumour showed evidence of clinical regression, but scattered apoptotic bodies were still seen when there was no residual clinical disease and within sheets of normal epithelial cells. A small number of cells undergoing necrosis (karyorrhexis or nuclear pyknosis) were also seen in cytology specimens showing apoptotic cell death. This appeared less important and was accompanied by a mild neutrophilic inflammatory infiltrate, as opposed to apoptotic cell death, which occurs without evoking an inflammatory reaction. ${ }^{15}$ This mimics the clinical situation with inflammation seen early in treatment, but ongoing reduction in tumour size continues without inflammation. We did not use additional techniques such as the TUNEL (terminal deoxynucleotidyl transferase mediated dUTP-biotin nick end labelling) assay to confirm apoptosis, but relied on the characteristic apoptotic morphology. Jerome and colleagues recently demonstrated the lack of specificity of the TUNEL assay with positive signal related to non-apoptotic cell death, artefacts of specimen fixation, and sectioning. ${ }^{16}$

The cellular changes that we observed in some normal ocular surface epithelial cells after MMC therapy are similar to those seen in Papanicolaou smears following radiation therapy for carcinoma of the uterine cervix ${ }^{17}$ and in transitional epithelium of the urinary tract following MMC. ${ }^{5} \mathrm{MMC}$ has been termed a radiomimetic agent with long term, possibly permanent, effects on tissues, ${ }^{18}$ and we confirm its radiomimetic effects on the ocular surface cytology following its topical use. Some normal epithelial cells may become very enlarged, up to six times normal size, due to increased amounts of cytoplasm, which may contain one to numerous vacuoles. This may be accompanied by increased nuclear size with nuclear wrinkling and apparent nuclear irregularity or hyperchromasia, but the critical issue is that the nuclear/cytoplasmic ratio remains within normal limits. The increase in nuclear and cell size in both radiation and MMC injury has been attributed to interference with cell division due to DNA damage. The mechanism of the cytoplasmic vacuolation is less clear, but dilatation of endoplasmic reticulum has been noted on ultrastructural examination of the vacuolated cells in radiation injury (personal communication with Dr John Papadimitriou) and this is presumably also the case with MMC injury. Such changes were seen in our first samples taken 4 weeks after commencement of
MMC therapy and cytomegalic cells were still observed 8 months after MMC therapy. Longer follow up is required and we are currently in the process of collecting such data. The persistence of MMC related changes varies from patient to patient, as patient 4 in our series had prominent changes at 8 and 12 weeks (Fig 2), but normal epithelium at 17 weeks. Cytological changes in urinary samples persist for up to 30 months after starting MMC for transitional cell carcinoma of bladder. ${ }^{5}$ However, the course of MMC for bladder cancers includes a total dose of $470 \mathrm{mg}$ given over 12 months, compared with much lower doses and shorter time courses $(0.04 \%$ for 7 days out of 14, repeated for two or three cycles) used in ocular surface neoplasia. The rationale for using MMC therapy in cycles of 7 days separated by 7 days off treatment to allow recovery/repair of normal cells is similar to that used in fractionation of radiation dose for treatment of systemic cancers.

The distinction of MMC related changes from malignant or dysplastic cells in impression cytology specimens can be made when the cell border of the cell is clearly visible and the nuclear/cytoplasmic (N/C) ratio can be estimated. Despite the enlarged nucleus seen in some MMC affected cells, the cytoplasm is also markedly increased in volume so that a normal N/C ratio is observed in the MMC associated atypical cells, but an increased ratio is seen in dysplastic cells. Differentiation becomes difficult in those cells with large hyperchromatic nuclei where the cell outline is not clearly defined, because of overlapping cells or attenuation of the vacuolated cytoplasm, so it is critical to study those cells where cell size can be assessed clearly. Our study has been a qualitative one to date, but quantitative studies of cell and nuclear size, nuclear chromatin texture, and nuclear features similar to those studied in cervical intraepithelial neoplasia are in progress. ${ }^{19}$ Although our data relate to impression cytology of the ocular surface, similar changes would be expected in spatula obtained cytology specimens.

Nadjari and colleagues in the only previous published study of ocular surface cytology after MMC, report therapy induced cytological changes 2 weeks after completion of the course of mitomycin therapy in all smears. ${ }^{7}$ The authors characterised these changes as degenerative-chromatin clumping, nuclear pyknosis, cytoplasmic vacuolisation and rupture and reactive - a mixture of normal sized and enlarged cells with large nuclei, occasional cytoplasmic vacuolisation, but normal N:C ratio and finely granular chromatin. Our series showed similar findings. Using DNA cytometry, Nadjari and colleagues demonstrated euploid polyploidisation of non-neoplastic squamous cells with stem lines at $2 \mathrm{c}, 4 \mathrm{c}$ and sometimes at $8 \mathrm{c}$.

Salomão and colleagues reported changes, which could mimic malignancy in conjunctival biopsies after topical MMC therapy for primary acquired melanosis (PAM) with atypia. ${ }^{8}$ Findings included alterations in the superficial cells of the conjunctival epithelium- 
occasional apoptotic cells, enlarged hyperchromatic or "smudged" nuclei and cytoplasmic eosinophilia seen in biopsies taken 3-6 weeks after ending MMC. Demirci and colleagues reported their longer term follow up of conjunctival histology, after mitomycin therapy for malignant melanoma of conjunctiva and PAM. ${ }^{9}$ Biopsies, taken at times ranging from 4 months to 44 months, revealed regionally variable conjunctival epithelial atrophy, dyskeratosis, focal keratinisation, occasional pyknotic nuclei with focal nuclear pleomorphism in the epithelium at 4 months. Subepithelial chronic inflammation proportional to the degree of atrophy and/or keratosis of epithelium was also noted. Although the degree of epithelial atrophy was quite marked (only 1-2 cells thick), the authors noted that this was clinically insignificant.

OSSN is recognised to be a multifocal disease with proclivity for recurrences after excisional biopsy, especially in cases with incomplete resection on histology. ${ }^{20}{ }^{21}$ Topical MMC offers an alternative to repeated excisional biopsies, as these often involve the limbus, and can result in limbal stem cell deficiency, if the dissection is extensive. Younger patients with recurrent and aggressive disease, such as the 44 year old woman in our series, are therefore good candidates for MMC therapy. Follow up of such patients involves regular clinical review with photography with the use of impression cytology as an adjunct to diagnosis. Unlike the situation in the urinary bladder, where the epithelium and any lesion exfoliating cells for cytology are not visible without an endoscopic procedure and anaesthesia, lesions of OSSN are usually clearly visible by the ophthalmologist. Impression cytology can be useful in monitoring for recurrent OSSN if the cytopathologist is given full clinical details of MMC therapy, and is aware of the cytological changes induced by the drug. Close liaison between the pathologist and clinician is therefore essential for interpretation of the cytological findings in the clinical context. Although our study to date has not shown any evidence of long term damage to ocular surface by MMC therapy, such as development of cytological signs of limbal stem cell dysfunction, continued longer term monitoring will be essential, particularly in those patients with multiple recurrences.
1 Frucht-Pery J, Rozenmann Y. Mitomycin C therapy for corneal intra-epithelial neoplasia. Am f Ophthalmol 1994; 117:164-8.

2 Frucht-Pery J, Sugar J, Baum J, et al. Mitomycin C treatment for conjunctival- corneal intraepithelial neoplasia. A multicenter experience. Ophthalmology 1997;104: 2085-93.

3 Nolan GR, Hirst LW, Wright RG, et al. Application of impression cytology to the diagnosis of conjunctival neoplasms. Diagn Cytopathol 1994;11:246-9.

4 Tole D, McKelvie PA, Daniell M. The reliability of impression cytology for the diagnosis of ocular surface squamous neoplasia employing the biopore membrane. Br f Ophthalmol 2001 (in press).

5 Koshikawa T, Leyh H, Schenck U. Difficulties in evaluating urinary specimens after local mitomycin therapy of bladder cancer. Diagn Cytopathol 1989;5:117-21

6 Maier U, Simak R, Neuhold N. The clinical value of urinary cytology: 12 years' experience with 615 patients. F Clin Pathol 1995;48:314-17.

7 Nadjari B, Kersten A, Ross B, et al. Cytologic and DNA diagnosis and therapy monitoring of squamous cell carcinoma in situ and malignant melanoma of the cornea and conjunctiva. Analyt Quant Cytol Histol 1999;21:38796.

8 Salomão DR, Mathers WD, Sutphin JE, et al. Cytologic changes in the conjunctiva mimicking malignancy after topical mitomycin C chemotherapy. Ophthalmology 1999; 106:1756-61.

9 Demirci H, McCormick SA, Finger PT. Topical mitomycin chemotherapy for conjunctival malignant melanoma and primary acquired melanosis with atypia: clinical experience with histopathologic observations. Arch Ophthalmol 2000; 118:885-91.

10 Thiel MA, Bossart W, Bernauer W. Improved impression cytology techniques for the immunopathological diagnosis of superficial viral infections. Br f Ophthalmol 1997;81: 984-8.

11 Chabner BA, Allegra CJ, Curt GA, et al. Antineoplastic agents. In: Harmnn JG, Limbird LE, Molinoff PB, Ruddon, Goodman Gilman, eds. Goodman and Gilman's the pharmacological basis of therapeutics. A, 9th ed. New the pharmacological basis of therapeuti

12 Rich T, Allen RL, Wyllie AH. Defying death after DNA damage. Nature 2000;407:777-83.

13 Fisher DE. Apoptosis in cancer therapy:crossing the threshold. Cancer 1994;539-42.

14 Kelly JD, Williamson KE, Weir HP, et al. Induction of apoptosis by mitomycin $\mathrm{C}$ in an ex-vivo model of bladder cancer. BfU Int 2000;85:911-17

15 Kerr JFR, Wyllie AH, Currie AR. Apoptosis: a basic biological phenomenon with wide-ranging implications in tissue kinetics. Br f Cancer 1972;26:239-57.

16 Jerome KR, Vallan C, Jaggi R. The TUNEL assay in the diagnosis of graft-versus-host disease:caveats for interpretation. Pathology 2000;32:186-90.

17 Graham R. Cellular effects of radiation during treatment. In: The cytologic diagnosis of cancer. Chapter 12 . Philadelphia: WB Saunders, 1972:155-76.

18 Sugar A. who should receive mitomycin-C after pterygium? (editorial). Ophthalmology 1992;99:1645-6.

19 Keenan S, Diamond J, McGluggage G, et al. A comparison of staining methods for analysis of chromatin structure in cervical intra-epithelial neoplasia (CIN) by computerized texture analysis. Proceedings of XIIIth International Congress on Diagnostic Quantitative Pathology, Adelaide, 16-20 Oct 2000:53

20 Tabin G, Levin S, Snibson G, et al. Late recurrences and the necessity for long-term follow-up in corneal and conjunctival intraepithelial neoplasia. Ophthalmology 1997;104:48592.

21 Lee GA, Hirst LW. Retrospective study of ocular surface neoplasia. Aust NZ F Ophthalmol 1997;25:269-76 